\title{
Optimization of Machining Parameters Using the Taguchi and ANOVA Analysis in the Face Milling of Aluminum Alloys AL7075
}

\author{
Borislav SAVKOVIĆ, Pavel KOVAČ, Antun STOIĆ, Branislav DUDIĆ
}

\begin{abstract}
This paper examines the influence of the cutting parameters on the cutting forces and the surface roughness at the face milling process when machining aluminum alloy 7075 is obtained by the new SSM casting process. The parameters of the milling process are the cutting speed, the feed per tooth and the depth of cut. The experiments were performed according to the Taguchi method according to the L 9 plan and the factors varied at three levels. For analysis of the effects of these parameters $S / \mathrm{N}$ ratio is used. In addition, ANOVA analysis was performed, i.e. analysis of the variance of the selected parameters. The analysis of the results shows that the optimal combination for the cutting force is the choice of a minimum level for all tested parameters. In contrast, for average arithmetic roughness, the optimal processing regime is achieved with minimum values for cutting speed and feed per tooth, whilst it is preferable to choose the cutting depth at the median level for the observed range. In addition, the study shows that the Taguchi method is suitable for solving the problem, where the research was carried out with a minimum number of tests compared to a full factorial experimental plan.
\end{abstract}

Keywords: aluminum alloy; ANOVA analysis; cutting parameters; Taguchi method

\section{INTRODUCTION}

The problem in the research that is also encountered, and which is always relevant in processes that deal with material processing, is certainly the optimization of the parameters that affect the values that define the favorable or unfavorable material. A large number of scientists have given their proposals and their solutions to find the most favourable system setting with a realization plan that yields the least losses, or the highest profit. The selection and application of an adequate optimization model to the process of milling is a problem that is largely represented in the research sector [1]. According to the previous one, one of the problems is certainly determining the value of input parameters of the processing depending on the target function, ie the output characteristics of the milling process.

In today's economic systems around the world, different production methods and access to quality are used around the world-depending on what the manufacturer wants to achieve, how familiar he is with the available capabilities, and the applicability of a particular method to a particular production system $[2,3]$. One of the possible approaches to quality is the use of the Taguchi method, which has the most widespread practical use [4].

The greatest contribution to this method is seen in the field of experiment planning. Taguchi developed the idea that products and processes can be so shaped as to be under the influence of the environment as little as possible. Such an approach is called a robust plan (design). Taguchi method is based on the concept of partial factorial experiment.

Accordingly, it can be said that one of the aims of the research is to optimize the parameters of the machining process by milling using the Taguchi method, which starts from the new experiment planning system, i.e. orthogonal arrays. Precisely this method for modelling and optimization, uses its stochastic nature that is suitable for such multifunctional optimization problems within the search space of possible solutions.
A review of the literature sources shows the Taguchi method for the treatment of milling process. Thus in [5] we see that the authors deal with the optimization of the process parameters in laser processing and all the minimization of the roughness of the surface treated. Research in this paper was carried out on aluminum alloy 6061. Consequently, it can be concluded that this area is still interesting for research, that is, the optimization of parameters on new alloys has not been sufficiently investigated $[6,7]$. Another work, which certainly deserves readers' attention, is the work [8] where authors adapt parameter optimization in the milling process of AISI 1045 materials. The problem in this paper is focused on the search for minimum tool wear, all for the purpose of better productivity of the machining process. The obtained optimization results show that cutting speed has the greatest impact on the tool's life. Consequently, in subsequent surveys, surely the cutting speed should be considered as a factor that needs to be optimized.

Among the authors whose works in the field of material removal must be mentioned and who made a significant contribution in the introduction of new methods of optimization, the Taguchi methods are the papers from the group [9-12]. In these works, the authors perform optimization of parameters in order to minimize the output characteristics of the cutting process.

In recent years, there has been an increasing interest in using the Taguchi methods in artificial neural network training (ANN). The advantages offered by ANN are numerous and are achieved by creating high performance models. However, determining the architecture parameters and training ANN remains a difficult task. Usually, these parameters are determined by the so-called. 'probes and errors' where a large number of models are created and compared with each other. In the paper [13], the Taguchi method is used for optimizing ANN parameters, trained by the Levenberg-Marke algorithm. Application of this approach is illustrated by the case study to model the resulting cutting force while turning. Optimal levels of parameters have been identified using the analysis of variance and mean values. Analyses and experiments show that the selection of optimal ANN parameters can be 
determined in a systematic way, avoiding the long-term 'trial and error' procedure.

In addition to the Taguchi method, other types of optimization can certainly be found in literary sources, among which the optimization of parameters is especially emphasized through ANOVA analysis. This model of optimization applied to cutting processes is aimed at reducing production costs and achieving the required product quality. Consequently, determining the optimal cutting parameters is essential. In the paper [14], the Taguchi method was used to minimize the roughness of the polyamide PA-6 surface in the turning process. The influence of four cutting parameters was analyzed: cutting speed, feed, depth of cut and radius of the tip of the tool and their influence on the value of average arithmetic roughness $\left(R_{\mathrm{a}}\right)$ based on standard $L_{27}$ Taguchi orthogonal lines. Based on ANOVA analysis, optimal cutting parameters are determined, as well as the level of their significance. In addition to the regression analysis, $\mathrm{K}$. Palanikumar [15] also uses ANOVA variance analysis to determine the optimal process parameters, all in order to minimize the surface roughness.

Also in the literature sources, many analytical methods that have been developed and used to predict the surface roughness parameters can be found in [16-18]. The application of ANOVA analysis is also present in the works dealing with the optimization of other output characteristics of the cutting process [19]. M.A. Lajis [20] developed a mathematical model for predicting the tool life of the hardened steel milling tool. Alauddinel et al. [21] presented a developed mathematical model for the stability of tools for machining steel for automatic milling using high cutting speeds in dry machining. In the paper [22], the authors presented results based on the ANOVA analysis of the surface roughness of parts made with multiprocessing. By analyzing literary sources, it can be noticed that there are not many works that applied ANN and Fuzzy logic to the experimental results obtained and compiled and analyzed using the Taguchi method and ANOVA analysis, all for the purpose of modeling and optimizing machining by milling.

According to the foregoing, it can be concluded that the Taguchi method and ANOVA analysis are applied to the processes involved in the removal of material in expansion. This is especially present on new materials for which it is necessary to determine the optimal processing regimes, all for the purpose of the most favorable output characteristics of the process. It can be said with certainty that no composite part produced by conventional processing machines by removing material can skip the milling operation, and as such it is suitable for optimizing processing parameters, which is the goal of this paper.

\section{EXPERIMENTAL PART}

Experimental tests were carried out on aluminum alloy 7075 (Al-Zn-Mg-Cu), which was cast with a new casting method, that is, the SSM (Semi Solid Metal) process. Aluminum alloy 7075 belongs to aluminum alloys for crushing (plastic deformation). The alloys 7075 have high mechanical properties, good machinability and the applicability of thermal processes, but have good corrosion resistance [23]. They belong to the group of "hard alloys".
They are also often used in the aviation industry and military applications. They are applied in the form of sheets, plates, wires, rods, extruded products, structural shapes, pipes, forgings etc. [24]. Fig. 1 shows the typical microstructure of the tested alloys of $\mathrm{Al} \mathrm{4,4 \%} \mathrm{Cu}$ obtained by the SSM process by casting. Tab. 1 shows the chemical composition of the investigated alloys. The main difference between the alloys obtained by this method is that the aluminum alloy cast by conventional means has a larger structure ( $\alpha$ solid solution) than the alloys molded by the SSM process. Also, the amount of eutectic is different and is higher in SSM, which is associated with a grain microstructure and the breakdown of dendrite with argon gas [25]. The width and length of all the workpieces was $100 \mathrm{~mm}$ and the thickness was $15 \mathrm{~mm}$. The chemical composition of the alloy 7075 is given in Tab. 1 .

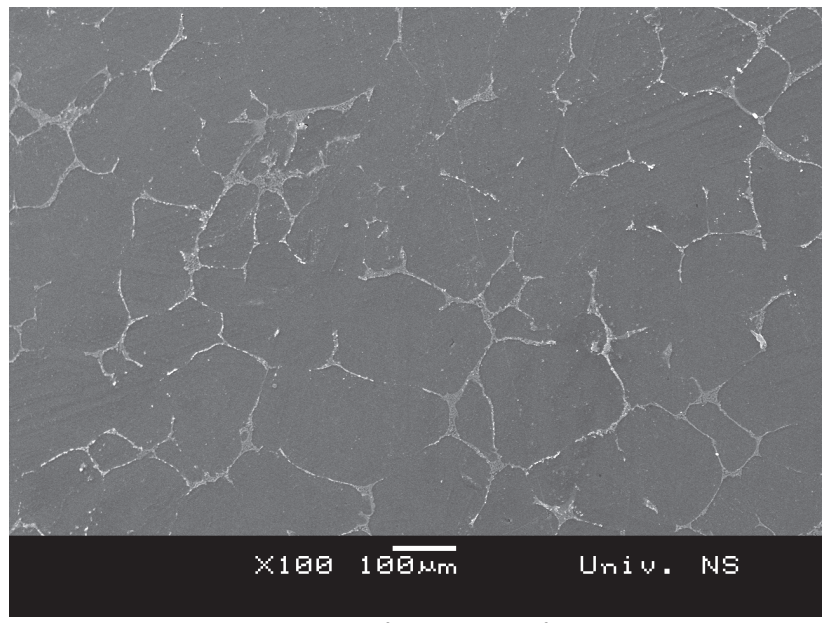

Figure 1 Microstructure of tested alloys of aluminum alloy

Table 1 Chemical composition of alloy 7075
\begin{tabular}{|c|c|c|c|c|c|c|c|c|}
\hline $\begin{array}{c}\text { Basic } \\
\text { element }\end{array}$ & $\mathrm{Zn}$ & $\mathrm{Mg}$ & $\mathrm{Cu}$ & $\mathrm{Cr}$ & $\mathrm{Fe}$ & $\mathrm{Si}$ & $\mathrm{Mn}$ & $\mathrm{Ti}$ \\
\hline $\mathrm{Al}$ & 5,8 & 2,52 & 1,65 & 0,2 & 0,18 & 0,1 & 0,025 & 0,025 \\
\hline
\end{tabular}

The experiment was performed on a vertical milling machine FSS-GVK-3 with a face milling head $\phi 100 \mathrm{~mm}$, with interchangeable cutting inserts, with the following characteristics: number of teeth $z=1$, toot cutting edge angle $\kappa=75^{\circ}$, tool rake $\gamma=0^{\circ}$. Insert made of hard metal quality $\mathrm{K} 20$, the following features $(l=I C=12,7 \mathrm{~mm} ; s=$ $\left.3,18 \mathrm{~mm} ; b_{s}=1,4 \mathrm{~mm} ; b_{\varepsilon}=1,4 \mathrm{~mm}\right)$.

As the output characteristics of the process, the cutting force and the roughness of the treated surface were selected, as the most commonly used machinability $[1,6]$. Measurement of the cutting force was carried out using the measuring system shown in Fig. 2. The central part of the system is virtual instrumentation. Virtual instrument is designed to allow easy monitoring of the voltage with a dynamometer, which corresponds to the cutting force components $F_{x}, F_{y}$ and $F_{z}$ during milling operation. Fig. 3 shows an example of appearance of orthogonal components of cutting force $F_{x}, F_{y}$ and $F_{z}$ pattern, per one revolution of one tooth face milling tool, when versus time for presented constant cutting conditions. 


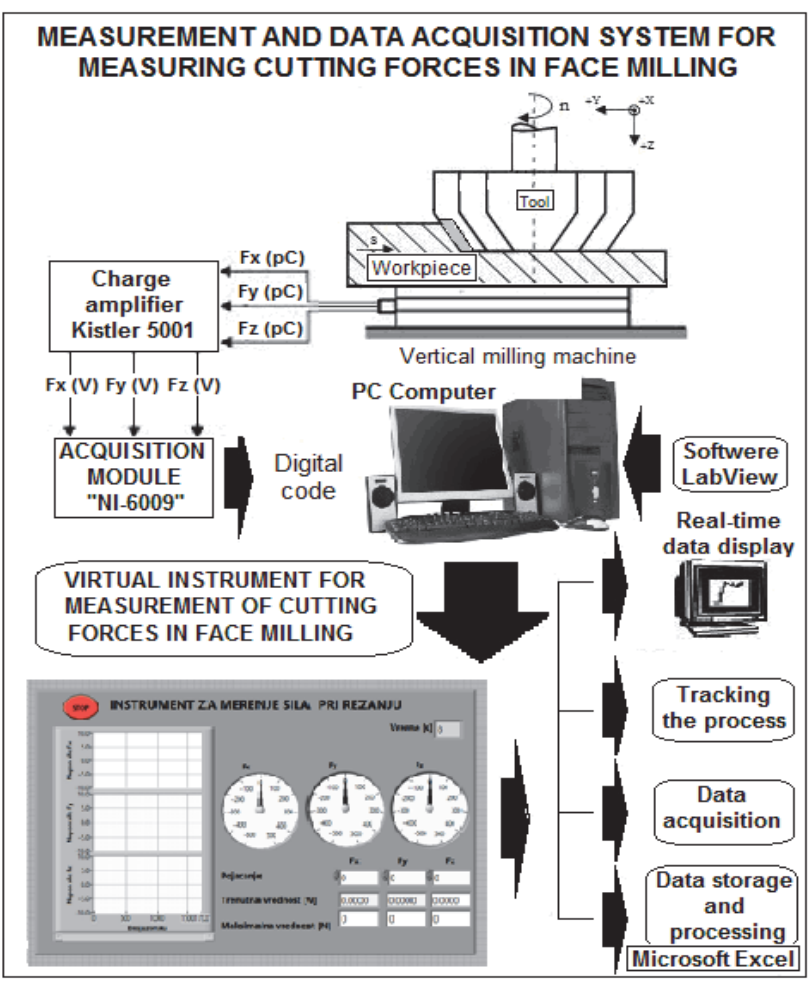

Figure 2 Measurement scheme for face milling machining

\section{Orthogonal cutting forces}

Tool: head for milling $\phi 100, \mathrm{~mm}\left(\kappa=75^{\circ}, \gamma=0^{\circ}\right), \mathrm{r}$ Material of workpiece: Al 7075-SSM

Regimes: $v=223,05, \mathrm{~m} / \mathrm{min} ; \mathrm{a}=\mathbf{2}, \mathbf{6}, \mathrm{mm}$;

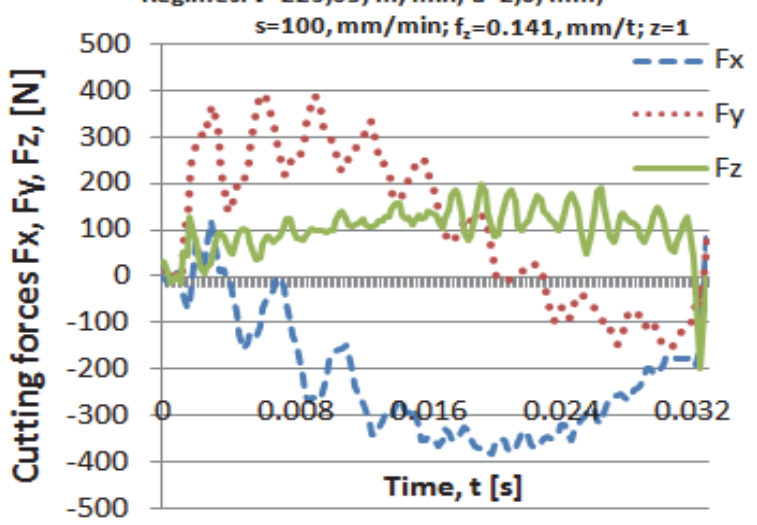

The components of the resulting cutting force

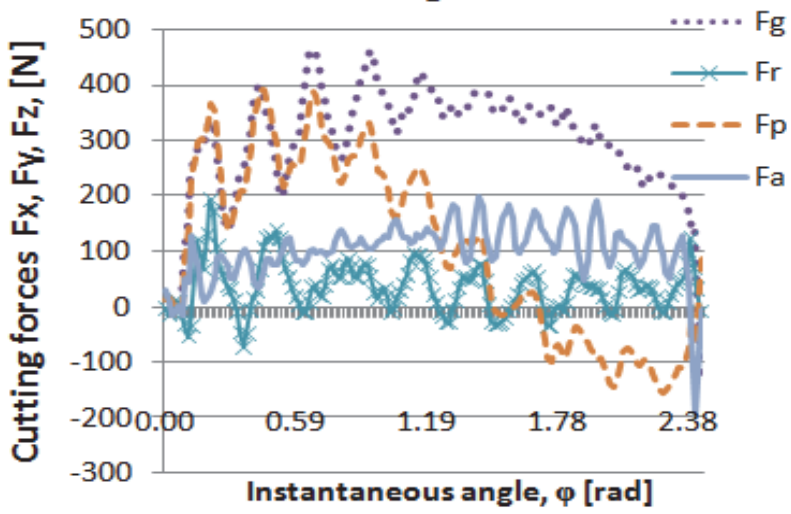

Figure 3 Converting orthogonal to the components of the resulting cutting forces

In the case of the acquisition of the $F_{x}, F_{y}$ and $F_{z}$ cutting force components, the transfer of the component is: $F_{c^{-}}$ main cutting force, $F_{r}$-radial force component $F_{p}$-force component propagating the $F_{a}$-axial force component defined through Eq. (1) - Eq (4) illustrated in the scheme in Fig. 4.

$$
\begin{aligned}
& F_{c}=-F_{x} \cdot \sin \varphi+F_{y} \cdot \cos \varphi \\
& F_{p}=F_{c} \cdot \cos \varphi+F_{r} \cdot \sin \varphi=F_{y} \\
& F_{r}=F_{x} \cdot \cos \varphi+F_{y} \cdot \sin \varphi \\
& F_{a}=F_{z}
\end{aligned}
$$
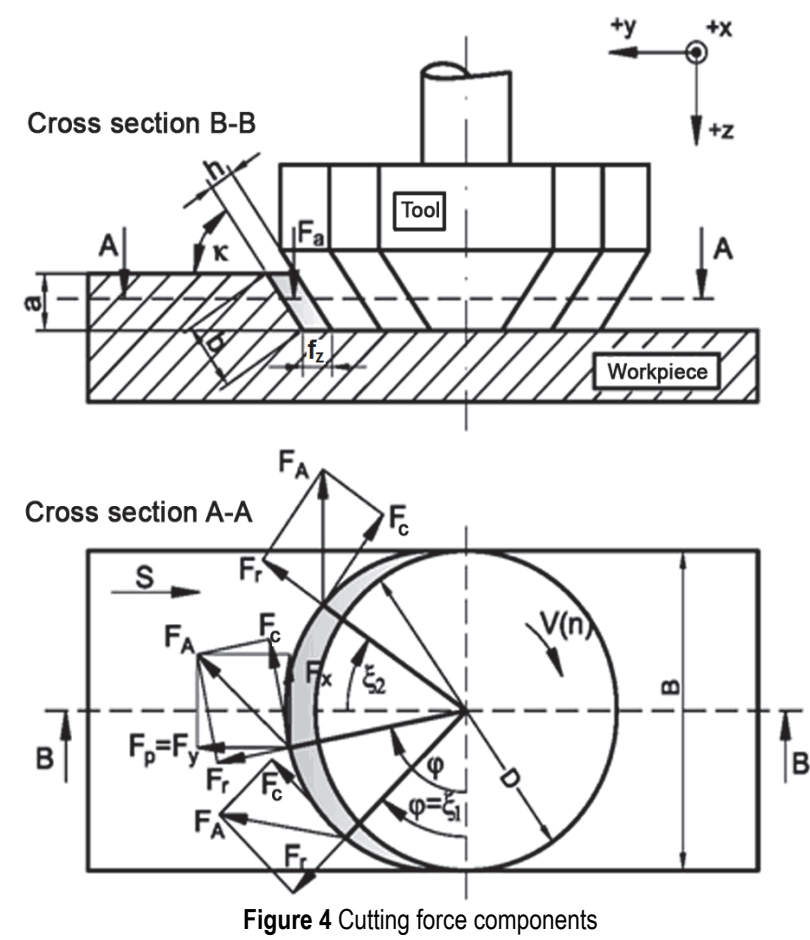

For the purposes of this research, i.e. measuring the roughness of the machined surface was used the device "MarSurf PS1". The maximum scaling range is $350 \mu \mathrm{m}$ (from $-200 \mu \mathrm{m}$ to $+150 \mu \mathrm{m}$ ). This device meets the standards of the International Organization for Standardization DIN EN ISO 3.274.

\section{OPTIMIZATION OF DATA}

After designing and performing the experiment, as well as the measurement of the output, the analysis of the results obtained followed. The result of the analysis is a set of coefficients that determine the relationships between the factors of experiments and outputs (measured quality characteristics). The usual way of analyzing and summarizing the results is via ANOVA (variation analysis) of the table.

When planning the experiment, the selected $L_{9}\left(3^{4}\right)$

\begin{tabular}{|c|c|c|c|c|}
\hline \multirow{2}{*}{ Designation } & \multirow{2}{*}{ Name factors } & \multicolumn{3}{|c|}{ Levels } \\
\hline & & 1 & 2 & 3 \\
\hline$A$ & Cutting speed $v / \mathrm{m} / \mathrm{s}$ & 2,35 & 3,71 & 5,86 \\
\hline$B$ & Feed per tooth $f_{\mathrm{z}} / \mathrm{mm} / \mathrm{t}$ & 0,089 & 0,141 & 0,223 \\
\hline$C$ & Cutting depth, $a / \mathrm{mm}$ & 0,5 & 1,14 & 2,6 \\
\hline
\end{tabular}
experimental model with three factors that vary in three levels, Tab. 2.

Table 2 Factors and levels of variation 
Signal to noise ratio and orthogonal array are two major tools used in robust design. The $S / N$ ratio characteristics can be divided into three categories when the characteristic is continuous: nominal is the best, smaller the better and larger is better characteristics. For the minimal main cutting force $F_{\mathrm{c}}$ and the arithmetic mean roughness $R_{\mathrm{a}}$, the solution is "smaller is better", and $S / N$ ratio is determined according to the following equation:

$S / N=-10 \log \left(\frac{1}{n}\right) \sum_{i=1}^{n} y_{i}^{2}$ where $n$ is the number of replication and $y_{i}$ is the measured value of output variable.

The orthogonal matrix with the measured main cutting forces $F_{\mathrm{c}}$ and the mean arithmetic surface roughness $R_{\mathrm{a}}$ is shown in Tab. 3, where the error of the experiment is denoted by $D$. Due to better quality analysis, it is necessary to have more data for measuring one and the same experiment, accordingly experiments were repeated three times.

Table 3 Orthogonal matrix with measured main cutting forces $F_{\mathrm{c}}$ and average arithmetic roughness of the machined surface $R_{\mathrm{a}}$

\begin{tabular}{|c|c|c|c|c|c|c|c|c|c|c|}
\hline \multirow{3}{*}{ No. } & \multicolumn{4}{|c|}{ Experiment plan } & \multicolumn{6}{|c|}{ Measured values } \\
\hline & $A$ & $B$ & $C$ & $D$ & \multirow{2}{*}{$F_{\mathrm{c} \text { i1 }}$} & \multirow{2}{*}{$F_{\mathrm{ci} 2}$} & \multirow{2}{*}{$F_{\mathrm{c} \text { i3 }}$} & \multirow{2}{*}{$R_{\text {a i1 }}$} & \multirow{2}{*}{$R_{\text {a i2 }}$} & \multirow{2}{*}{$R_{\mathrm{a} \text { i3 }}$} \\
\hline & $v$ & $f_{\mathrm{z}}$ & $a$ & Error exp. & & & & & & \\
\hline 1 & 1 & 1 & 1 & 0 & 85 & 91 & 80 & 0,817 & 0,821 & 0,920 \\
\hline 2 & 1 & 2 & 2 & 0 & 223 & 227 & 119 & 0,758 & 0,774 & 0,713 \\
\hline 3 & 1 & 3 & 3 & 0 & 631 & 642 & 622 & 1,259 & 1,343 & 1,259 \\
\hline 4 & 2 & 1 & 2 & 0 & 170 & 180 & 162 & 0,568 & 0,680 & 0,634 \\
\hline 5 & 2 & 2 & 3 & 0 & 423 & 466 & 401 & 0,921 & 1,093 & 0,941 \\
\hline 6 & 2 & 3 & 1 & 0 & 145 & 150 & 140 & 1,303 & 1,369 & 1,618 \\
\hline 7 & 3 & 1 & 3 & 0 & 332 & 340 & 325 & 0,731 & 0,796 & 0,660 \\
\hline 8 & 3 & 2 & 1 & 0 & 137 & 146 & 134 & 1,048 & 1,089 & 0,979 \\
\hline 9 & 3 & 3 & 2 & 0 & 305 & 312 & 296 & 1,257 & 1,422 & 1,517 \\
\hline
\end{tabular}

\section{ANALYSIS OF RESULTS}

The calculated $S / N$ ratio for the selected "smaller is better" criterion on the base Eq. (5) are shown in Tab. 4. For both output characteristics of the process, the mean measured values were also used, based on which ANOVA analysis was carried out.

\subsection{TAGUCHI METHOD}

Based on the obtained $S / N$ ratio values, graphs for the main cutting force $F_{\mathrm{c}}$, Fig. 5 are defined. The shown $S / N$ relations for the dotted points on the graphs are obtained as the mean value of the corresponding factor with the same level. Based on the intensity of the $S / N$ ratio and the crossing points, it can be seen that the greatest impact on the value of the main cutting force has a depth of cut, then a feed per tooth, while the impact of the cutting speed is negligible. It can also be noted that for all three factors $A, B$ and $C$ the highest $S / N$ value is at the first level $(A=1, B=$ $1, C=1)$, ie these levels would represent the optimal values of the parameters.

Table 4 Calculated values of $S / N$ ratio for the selected criterion "smaller is better"

\begin{tabular}{|c|c|c|c|c|c|c|c|c|}
\hline \multirow{3}{*}{ No. } & \multicolumn{4}{|c|}{ Experiment plan } & \multirow{3}{*}{$\begin{array}{l}\text { Mean measured value } \\
\qquad F_{\mathrm{ci}}\end{array}$} & \multirow{3}{*}{$\begin{array}{c}S / N \text { ratio } \\
S / N_{i}\end{array}$} & \multirow{3}{*}{$\begin{array}{c}\text { Mean measured value } \\
\qquad R_{\mathrm{ai}}\end{array}$} & \multirow{3}{*}{$\begin{array}{c}S / N \text { ratio } \\
S / N_{i}\end{array}$} \\
\hline & $A$ & $B$ & $C$ & $D$ & & & & \\
\hline & $v$ & $s_{1}$ & $a$ & Error exp. & & & & \\
\hline 1 & 1 & 1 & 1 & 0 & 85,333 & $-38,6344$ & 0,853 & 1,370878 \\
\hline 2 & 1 & 2 & 2 & 0 & 189,667 & $-45,8516$ & 0,748 & 2,512929 \\
\hline 3 & 1 & 3 & 3 & 0 & 631,667 & $-56,0105$ & 1,287 & $-2,19568$ \\
\hline 4 & 2 & 1 & 2 & 0 & 170,667 & $-44,6511$ & 0,627 & 4,026779 \\
\hline 5 & 2 & 2 & 3 & 0 & 430,000 & $-52,6865$ & 0,985 & 0,104952 \\
\hline 6 & 2 & 3 & 1 & 0 & 145,000 & $-43,2308$ & 1,430 & $-3,14562$ \\
\hline 7 & 3 & 1 & 3 & 0 & 332,333 & $-50,433$ & 0,729 & 2,720314 \\
\hline 8 & 3 & 2 & 1 & 0 & 139,000 & $-42,8661$ & 1,039 & $-0,33781$ \\
\hline 9 & 3 & 3 & 2 & 0 & 304,333 & $-49,669$ & 1,399 & $-2,93983$ \\
\hline
\end{tabular}

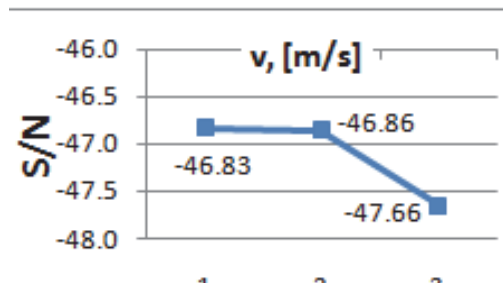

1
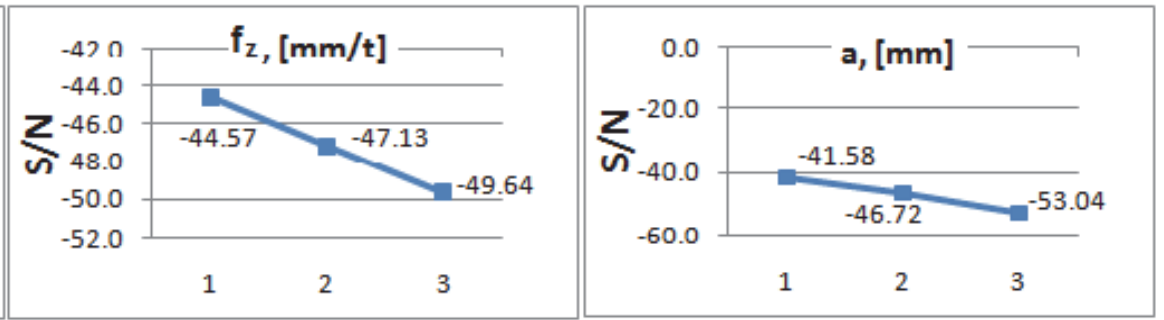

Figure 5 Diagram of factor $A, B, C$ for the main cutting force $F_{c}$

Based on the defined graphs, Fig. 6, one can see the influence of certain factors on the average arithmetic surface roughness $R a$. From the shown graphics, it is seen that the greatest effect is the feed per tooth, then the depth 
of cut and cutting speed. It can also be seen that for factor $A$ and $B$ the highest $S / N$ value is at the first level, and for factor $C$ at the second level $(A=1, B=1, C=2)$, or these levels represent optimal values.

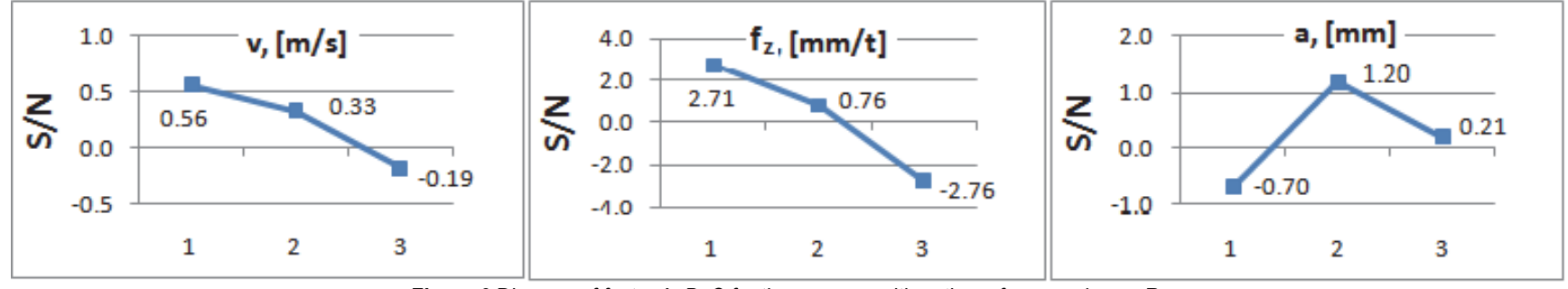

Figure 6 Diagram of factor $A, B, C$ for the average arithmetic surface roughness $R_{a}$

\subsection{ANALYSIS OF VARIANCE (ANOVA)}

When optimizing the parameters of the cutting regimen through ANOVA analysis, it is necessary to follow procedural steps. The first step is the formation of a summary table, that is, the formation of a table with the mean values of three repeated experiments, Tab. 4.

In step 2, the total sum of the output squares and the sum of the squares by factors as well as the sum of the squares of the error are calculated according to the following formulas:

Total sum of squares:

$S_{T}=\sum_{i=1}^{n} Y_{i}^{2}-\left(\left(\sum_{i=1}^{n} Y_{i}\right)^{2} / n\right)$

where: $n$-the number of experiments performed (here is $n$ $=9), Y_{i}$-is the output from the $i$-th execution of the experiment, $i=1,2, \ldots, n$

Sum of squares by factors:

$S_{p}=\sum_{j=1}^{t} \frac{\left(\sum Y_{p j}\right)^{2}}{t}-\frac{1}{n}\left(\sum_{i=1}^{n} Y_{i}\right)^{2}$

where: $p$-some of the factors $(A, B, C), t$-repetition of each level of factors (in this case it is 3 ), $\sum Y_{p j}$-sum of experimental results of the factor $\mathrm{p}$ on $\mathrm{j}$-th level. $j=1,2$, 3.

The sum of the squares for the error can be calculated as follows:

$S_{D}=S_{T}-S_{A}-S_{B}-S_{C}$

In the third step, it is necessary to determine the degree of freedom for each factor, error, and total value according to the following formulas:

$D F_{T}=n-1=9-1=8$

$D F_{A}=D F_{B}=D F_{C}=n_{E}-1=3-1=2$

$D F_{D}=D F_{T}-D F_{A}-D F_{B}-D F_{C}=8-2-2-2=2$

where: $n$-the number of experiments performed $n=9, n_{E}$ - number of factor variation levels $n_{E}=3$.
After that, in the fourth step it is necessary to determine the Variation by the following equations:

$V_{A}=\frac{S_{A}}{D F_{A}}, V_{B}=\frac{S_{B}}{D F_{B}}, V_{C}=\frac{S_{C}}{D F_{C}}, V_{D}=\frac{S_{D}}{D F_{D}}$

In the fifth step it is necessary to determine the calculation value of the Fischer test based on:

$F_{A}=\frac{V_{A}}{V_{D}}, F_{B}=\frac{V_{B}}{V_{D}}, F_{C}=\frac{V_{C}}{V_{D}}$

In the following Tab. 5 (step six) the initial ANOVA table with the filled values is presented, which are obtained according to the previously defined steps in the ANOVA analysis. The results shown refer only to the main cutting force $F_{\mathrm{c}}$.

Table 5 The initial ANOVA table with the filled values

\begin{tabular}{|c|c|c|c|c|}
\hline \multirow{2}{*}{ Designation } & $\begin{array}{c}\text { Degrees of } \\
\text { freedom }\end{array}$ & $\begin{array}{c}\text { Sum of the } \\
\text { square }\end{array}$ & Variations & $F$-test \\
\cline { 2 - 5 } & $D F$ & $S$ & $V$ & $F$ \\
\hline$A$ & 2 & 4886,88 & 2443,4 & 0,388 \\
\hline$B$ & 2 & 41736,9 & 20868,4 & 3,313 \\
\hline$C$ & 2 & 185454,5 & 92727,6 & 14,723 \\
\hline$D$ & 2 & 12596,5 & 6298,2 & \\
\hline Total & 8 & 244674,8 & & \\
\hline
\end{tabular}

$F$-test value for factor $A$ (cutting speed) $\leq 1$ which means that the variance that comes from these factors is not higher than the variance of the error. Accordingly, factor $A$ is removed which is not significant and is counted as an error in the next interaction.

The total sum of the squares does not change and is taken from step 2. The sum of the squares for the new error is calculated as the sum of the squares for the original error value summed with the sum of the squares of all the nonsignifying factors:

$S_{E}=S_{D}+S_{A}$

It is similar to Stephen's freedom of assembly error:

$D F_{E}=D F_{D}+D F_{A}$

Afterwards account the variation of assembly:

$V_{E}=\frac{S_{E}}{D F_{E}}$ 
$F$ statistics for factors that are not included in the gathering must be recalculated using a newly calculated variance error:

$F_{B}{ }^{\prime}=\frac{V_{B}}{V_{D}}, F_{C}{ }^{\prime}=\frac{V_{C}}{V_{D}}$

For these factors, a clear (complete) sum of the squares must be obtained:

$$
\begin{aligned}
& S_{B}{ }^{\prime}=S_{B}-\left(V_{E} \cdot D F_{B}\right) \\
& S_{C}{ }^{\prime}=S_{C}-\left(V_{E} \cdot D F_{C}\right) \\
& S_{E}{ }^{\prime}=S_{E}+\left(V_{E} \cdot\left(D F_{T}-D F_{E}\right)\right.
\end{aligned}
$$

The percentage factor participation is obtained by dividing the sum of the squares (newly calculated) for each factor with the total sum of the squares.

After removal of factor $A$, a new final ANOVA, Tab. 6 , is obtained, where a new assembly error is represented by the mark $E$.

Table 6 Calculated values in the final ANOVA table
\begin{tabular}{|c|c|c|c|c|c|}
\hline \multirow{2}{*}{ Designation } & $\begin{array}{c}\text { Degrees of } \\
\text { freedom }\end{array}$ & Variations & F-test & $\begin{array}{c}\text { Sum of the } \\
\text { square }\end{array}$ & $\begin{array}{c}\text { Percentage } \\
\text { share }\end{array}$ \\
\cline { 2 - 6 } & $D F$ & $V$ & $F^{\prime}$ & $S^{\prime}$ & $P / \%$ \\
\hline$B$ & 2 & 20868,4 & 4,77 & 32995,26 & 13,49 \\
\hline$C$ & 2 & 92727,6 & 21,21 & 176712,8 & 72,22 \\
\hline$E$ & 4 & 4370,85 & & 34966,81 & 14,29 \\
\hline Total & 8 & & & 244674,8 & 100 \\
\hline
\end{tabular}

In the following Tab. 7 the initial ANOVA table for the mean arithmetic roughness of the treated surface $R_{\mathrm{a}}$.

Table 7 The initial ANOVA table with the filled values

\begin{tabular}{|c|c|c|c|c|}
\hline \multirow{2}{*}{ Designation } & $\begin{array}{c}\text { Degrees of } \\
\text { freedom }\end{array}$ & $\begin{array}{c}\text { Sum of the } \\
\text { square }\end{array}$ & Variations & $F$-test \\
\cline { 2 - 5 } & $D F$ & $S$ & $V$ & $F$ \\
\hline$A$ & 2 & 0,01296 & 0,0064 & 0,612 \\
\hline$B$ & 2 & 0,63975 & 0,3198 & 30,208 \\
\hline$C$ & 2 & 0,05035 & 0,0251 & 2,378 \\
\hline$D$ & 2 & 0,02118 & 0,0105 & \\
\hline Total & 8 & 0,72425 & & \\
\hline
\end{tabular}

As with the main cutting force, the $F$-test factor $A$ factor (cutting speed) is $\leq 1$ which means that the variance that comes from these factors is no higher than the variance of the error. By removing factor $A$ that is not significant and re-calculating the error, the degree of freedom, variance, a new final ANOVA, Tab. 8, is obtained with new $F$-test values.

Table 8 Calculated values in the final ANOVA table

\begin{tabular}{|c|c|c|c|c|c|}
\hline \multirow{2}{*}{ Designation } & $\begin{array}{c}\text { Degrees of } \\
\text { freedom }\end{array}$ & Variations & F-test & $\begin{array}{c}\text { Sum of the } \\
\text { square }\end{array}$ & $\begin{array}{c}\text { Percentage } \\
\text { share }\end{array}$ \\
\cline { 2 - 6 } & $D F$ & $V$ & $F^{\prime}$ & $S^{\prime}$ & $P / \%$ \\
\hline$B$ & 2 & 0,0064 & 37,47 & 0,622684 & 85,98 \\
\hline$C$ & 2 & 0,3198 & 2,95 & 0,033285 & 4,59 \\
\hline$E$ & 4 & 0,00853 & & 0,068282 & 9,43 \\
\hline Total & 8 & & & 0,72425 & 100 \\
\hline
\end{tabular}

ANOVA analysis confirms that the main cutting force during the face milling of the aluminum alloy obtained by the SSM process has the greatest influence on the cutting depth. The impact of the shift is significant, but not critical, while the impact of the cutting speed is negligible. Error of $14.2 \%$ indicates that the next model inputs have an impact, and other factors of the process.

Also, ANOVA analysis confirms that the average arithmetic roughness of the machined surface $R_{a}$ measured during the face milling has the greatest influence on the feed to the tooth. The effect of cutting speed and cutting depth is not significant. The error of $9.4 \%$ indicates that, besides the input sizes, this model has the higher influence of other factors of the process.

The values for the analysis of the significance of the parameters are shown in Tab. 9, where the $F$-test values for the selected confidence level $(95 \%$ and $99 \%)$, the degree of freedom of the factor $\left(D F_{B}=D F_{C}=2\right)$ and the error rate

\begin{tabular}{|c|c|c|c|c|c|c|c|c|}
\hline \multirow{3}{*}{ 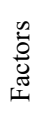 } & \multicolumn{2}{|c|}{$F$-Test calculated } & \multirow{2}{*}{\multicolumn{2}{|c|}{$\begin{array}{c}F \text {-Test } \\
\text { Table value }\end{array}$}} & \multicolumn{4}{|c|}{ Significance of factors } \\
\hline & \multirow{2}{*}{$\begin{array}{c}\text { for } F \mathrm{c} \\
F^{\prime}\end{array}$} & \multirow{2}{*}{$\begin{array}{c}\text { for } R \mathrm{a} \\
F^{\prime}\end{array}$} & & & \multicolumn{2}{|c|}{ for $F \mathrm{c}$} & \multicolumn{2}{|c|}{ for $R \mathrm{a}$} \\
\hline & & & $95 \%$ & $99 \%$ & $95 \%$ & $99 \%$ & $95 \%$ & $99 \%$ \\
\hline$B$ & 4,77 & 37,47 & \multirow{2}{*}{6.9943} & \multirow{2}{*}{18.000} & No & No & Yes & Yes \\
\hline$C$ & 21,21 & 2,95 & & & Yes & Yes & No & No \\
\hline
\end{tabular}
$\left(D F_{E}=4\right)$ are taken based on the Fischer distribution.

Table 9 Factor Significance

Note: the mentioned budget is valid for the analysis of factors that are mutually independent.

The verification of the proposed optimal parameter values is in Tab. 10. Optimal cutting regimes were obtained on the basis of the rule that the optimum value is the value for which we obtain the maximum $S / N$ ratio. There is a noticeable deviation of experimental values and results derived from the Taguchi method.

Table 10 Optimal values of the cutting regime

\begin{tabular}{|l|l|}
\hline $\begin{array}{l}\text { The resultant value of extra help } \\
\text { Taguchi methods: }\end{array}$ & $\begin{array}{l}\text { The resultant experimental } \\
\text { values: }\end{array}$ \\
\hline$S / N=-38,755 ; F_{\mathrm{c}}=86,646 \mathrm{~N}$ & $F_{\mathrm{c}}=85 \mathrm{~N}$ \\
\hline$S / N=3,996 ; R_{\mathrm{a}}=0,631 \mu \mathrm{m}$ & $R_{\mathrm{a}}=0,632 \mu \mathrm{m}$ \\
\hline
\end{tabular}

\section{CONCLUSIONS}

Optimization of parameters of milling process was carried out with the help of the Taguchi method, based on which the selection of optimal processing regimes was performed in order to minimize the output characteristics of the process state (machinability functions). An analysis of the parameters that have no effect on the output values of the functions has been carried out and accordingly they can be further increased in order to achieve as much productivity as possible, if only one selected function is observed. Results obtained using the Taguchi method and ANOVA analysis show good agreement. If more output characteristics of the process state are analyzed, it is necessary to perform a multi-criteria analysis for the observed functions.

Specifically, in this paper, the dependence of the main cutting force and the roughness of the surface relative to the three cutting regime parameters in milling is considered, namely cutting speed, feed per tooth and cutting depth. Experimental investigations were carried out on aluminum alloy 7075 by a new process of casting, ie SSM method, and as such is challenging to investigate its 
optimal. From the analysis of the methods used for optimization, the results indicate that among the influencing parameters the most important parameter is the cutting depth for the main cutting force, ie the feed per tooth for average arithmetic roughness.

In the tested interval, the optimum values of the cutting mode for the main cutting force are $\left(v=2,35 \mathrm{~m} / \mathrm{s}, f_{\mathrm{z}}=0.089\right.$ $\mathrm{mm} / \mathrm{t}$ and $a=0,5 \mathrm{~mm})$, while for the mean arithmetic roughness they are $\left(v=2,35 \mathrm{~m} / \mathrm{s}, f_{\mathrm{z}}=0.089 \mathrm{~mm} / \mathrm{t}\right.$ and $a=$ $1,14 \mathrm{~mm})$.

\section{REFERENCES}

[1] Simunovic, G., Simunovic, K., \& Saric, T. (2013) Modelling and Simulation of Surface Roughness in Face Milling. International Journal of Simulation Modelling. 12(3),141-153. https://doi.org/10.2507//JSIMM12(3)1.219

[2] Janekova, J., Fabianova, J., Fabian, M. (2019). Assessment of economic efficiency and risk of the project using simulation. International Journal of Simulation Modelling, 8(2), 242-253, https://doi.org/10.2507/IJSIMM18(2)467

[3] Kundrak, J., Molnar, V., \& Deszpoth, I. (2018). Analysis of Machining Time and Material Removal Performance as Factors Influencing Efficiency and Profitability. Vehicle and Automotive Engineering 2, 268-279. https://doi.org/10.1007/978-3-319-75677-6_22

[4] Király, A., Dobos, L., \& Abonyi, J. (2013). Economic oriented stochastic optimization in process control using Taguchi's method. Optimization and Engineering,14(4), 547-563. https://doi.org/10.1007/s11081-013-9237-3

[5] Lo, S. P., Chiu, J. T., Lin, H. Y. (2005). Rapid measurement of surface roughness for face-milling aluminum using laser scattering and the Taguchi method. The International Journal of Advanced Manufacturing Technology, 26(9), 1071-1077. https://doi.org/10.1007/s00170-004-2073-z

[6] Lazarević, D., Nedić, B., Marušić, V., Mišić, M., \& Šarkoćević, Ž. (2017). Regenerating the NC code in order to improve the surface quality. Tehnickki vjesnik, 24(2), 355362. https://doi.org/10.17559/TV-20161018122324

[7] Huang, X., Sun, J., \& Li, J. (2015). Effect of initial residual stress and machining-induced residual stress on the deformation of aluminium alloy plate. Strojniški vestnik, 61(2), 131-137. https://doi.org/10.5545/sv-jme.2014.1897

[8] Escalona, P. M., Diaz, N., \& Cassier, Z. (2012). Prediction of Tool Wear Mechanisms in Face Milling AISI 1045 Steel. Journal of Materials Engineering and Performance, 21(6), 797-808. https://doi.org/10.1007/s11665-011-9964-6

[9] Mia, M., Dhar, N. R. (2017). Optimization of surface roughness and cutting temperature in high-pressure coolantassisted hard turning using Taguchi method. The International Journal of Advanced Manufacturing Technology, 88(1-4), 739-753. https://doi.org/10.1007/s00170-016-8810-2

[10] Zębala, W. \& Kowalczyk, R. (2015). Estimating the effect of cutting data on surface roughness and cutting force during WC-Co turning with PCD tool using Taguchi design and ANOVA analysis. The International Journal of Advanced Manufacturing Technology, 77(9-12), 2241-2256. https://doi.org/10.1007/s00170-014-6382-6

[11] Sekulić, M., Kramar, D., Kovač, P., Gostimirović, M., \& Kopač, J. (2012). Application of Taguchi Method in The Optimization of High-Pressure Jet Assisted Turning Parameters. 3thInternational Conference on Sustainable Life in Manufacturing - SLIM, Istanbul, 7-10.

[12] Cetin, S. \& Kyvak, T. (2017). Optimization of the machining parameters for theturning of 15-5 ph stainless steels using the taguchi method. Materials and Technology, 51(1), 133-140. https://doi.org/10.17222/mit.2016.007
[13] Madić, M. J., Radovanović, M. R. (2011). Optimalani zbor parametara arhitekture i treniranja veštačke neuronske mreže primenomTaguči metode - studija slučaja. $F M E$, Transactions, 39(2), 79-86.

[14] Lazarević, D., Madić, M., Janković, P., \& Lazarević, A. (2012). Surface roughness minimization of polyamide Pa-6 turning by taguchi method. Journal of Production Engineering, 15(1), 29-32.

[15] Palanikumar, K., Muthukrishnan, N., \& Hariprasad, K. S. (2008). Surface roughness parameters optimization in machining A356/SiC/20p metal matrix composites by pcd tool using response surface methodology and desirability function. Machining Science and Technology, 12(4), 529545. https://doi.org/10.1080/10910340802518850

[16] Hrelja, M., Klancnik, S., Irgolic, T., Paulic, M., Jurkovic, Z., Balic, J., \& Brezocnik, M. (2014). Particle swarm optimization approach for modelling a turning process. Advances in Production Engineering \& Management, 9(1), 21-30. https://doi.org/10.14743/apem2014.1.173

[17] Hrelja, M., Klancnik, S., Balic, J., \& Brezocnik, M. (2014). Modelling of a turning process using the gravitational search algorithm. International Journal of Simulation Modelling, 13(1), 30-41, https://doi.org/10.2507/IJSIMM13(1)3.248

[18] Pare, V., Agnihotri, G., \& Krishna, C. (2015). Selection of optimum process parameters in high speed CNC end-milling of composite materials using meta heuristic techniques - A comparative study. Strojniški vestnik, 61(3), 176-186. https://doi.org/10.5545/sv-jme.2014.1914

[19] Chandrasekaran, M. \& Devarasidappa, D. (2014). Artificial neural network modeling for surface roughness predic-tion in cylindrical grinding of $\mathrm{Al}-\mathrm{SiCp}$ metal matrix composites and ANOVA analysis. Advances in Production Engineering \& Management, 9(2), 59-70. https://doi.org/10.14743/apem2014.2.176

[20] Lajis, M.A., Mustafizul, A. N. K., Nurul, A. K. M. A., Hafiz, A. M. K., \& Turnad, L. G. (2008). Prediction of Tool Life in End Milling of Hardened Steel AISI D2. European Journal of Scientific Research, 21(4), 592-602.

[21] Alauddinel, M., Baradie, M. A., \& Hashmi, M. S. J. (1997). Prediction of tool life in end milling by response surface methodology. Journal of Materials Processing Technology, 71(3), 456-465, https://doi.org/10.1016/S0924-0136(97)00111-8

[22] Šugár, P., Šugárová, J., \& Petrovič, J. (2018). The Effect of Process Parameters on Surface Finish of Metal Spun Parts. Tehnički vjesnik, 25(5), 1467-1471. https://doi.org/10.17559/TV-20150208190548

[23] Borojević, S., Lukić, D., Milošević, M., Vukman, J., \& Kramar, D. (2018). Optimization of process parameters for machining of Al 7075 thin-walled structures. Advances in Production Engineering \& Management, 13(2), 121-232. https://doi.org/10.14743/apem2018.2.278

[24] Stojanović, B. \& Ivanović, L. (2015). Application of aluminium hybrid composites in automotive industry. Tehnički vjesnik, 22(1), 247-251. https://doi.org/10.17559/TV20130905094303

[25] Kovac, P., Sidjanin L., Rajnovic, D., Savkovic, B., \& Wannasin. J. (2012). The Microstructure Influence on the Chip Formation Process of Al-Cu Alloy Cast Conventionally and in Semi Solid State. Metalurgija, 51(1), 34-38. 


\section{Contact information:}

Borislav SAVKOVIĆ, PhD, Assistant Professor,

(Corresponding author)

University of Novi Sad, Faculty of Technical Sciences,

Trg Dositeja Obradovića 6, 21000 Novi Sad, Serbia

E-mail: savkovic@uns.ac.rs

Pavel KOVAČ, PhD, Full Professor,

University of Novi Sad, Faculty of Technical Sciences,

Trg Dositeja Obradovića 6, 21000 Novi Sad, Serbia

E-mail: pkovac@uns.ac.rs

Antun STOIĆ, PhD, Full Professor

Mechanical Engineering Faculty in Slavonski Brod,

Trg Ivane Brlić Mažuranić 2, 35000 Slavonski Brod, Croatia

E-mail: astoic@sfsb.hr

Branislav DUDIĆ, PhD, Assistant,

Comenius University in Bratislava, Faculty of Management,

Odbojárov 10, P.O.BOX 9582005 Bratislava 25, Slovak Republic

E-mail: branislav.dudic@fm.uniba.sk 